\title{
Some Gastrointestinal Tract Characteristics of Karayaka Ram Lambs Slaughtered at Different Weights
}

\author{
Arda Yıldırım, ${ }^{1}$ Yüksel Aksoy, ${ }^{2}$ Nuh Ocak, ${ }^{3}$ and Zafer Ulutaş ${ }^{4}$ \\ ${ }^{1}$ Department of Animal Science, Faculty of Agriculture, University of Gaziosmanpaşa, 60240 Tokat, Turkey \\ ${ }^{2}$ Department of Food Processing, Bor Vocational School, University of Niğde, 51700 Niğde, Turkey \\ ${ }^{3}$ Department of Animal Science, Faculty of Agriculture, University of Ondokuz Mayıs, 55139 Samsun, Turkey \\ ${ }^{4}$ Department of Animal Production and Technologies, Faculty of Agricultural Sciences and Technologies, \\ University of Niğde, 51240 Niğde, Turkey
}

Correspondence should be addressed to Arda Yıldırım; arda.yildirim@gop.edu.tr

Received 13 March 2014; Accepted 6 July 2014; Published 15 July 2014

Academic Editor: Jesus L. Romalde

Copyright (C) 2014 Arda Yıldırım et al. This is an open access article distributed under the Creative Commons Attribution License, which permits unrestricted use, distribution, and reproduction in any medium, provided the original work is properly cited.

Thirty-one Karayaka ram lambs were slaughtered at different body weights $(30(n=7), 35(n=6), 40(n=7), 45(n=6)$, and $50(n=5) \mathrm{kg}$ of body weight at fast) to evaluate the growth of their gastrointestinal tract (GIT) characteristics, to determine the relationship among slaughter body weight (SBW) and empty body weight (EBW), whole GIT and segments, and the influence of slaughter weight on the $\mathrm{pH}$ of rumen, jejunum, and cecal contents. The effects of the SBW on GIT weight $(P<0.05)$, stomach $(P<0.001)$, and intestine $(P<0.05)$, the body length $(P<0.001)$ and caecum $(P<0.05)$, and the relative weights of GIT $(P<0.05)$, stomach $(P<0.001)$, and intestine $(P<0.001)$ were linear whereas that for the length of intestine were quadratic. The effect of SBW were quadratic $(P<0.05)$ on ratios of stomach to GIT weight and intestine length to intestine weight and rumen $\mathrm{pH}$ while, for the intestine to GIT weight ratio $(P<0.001)$ and caecum $\mathrm{pH}(P<0.05)$, this effect was linear. The results indicated that for all parameters studied, with the exception of intestinal length and cecal $\mathrm{pH}$, linear relationships were observed with SBW indicating steady growth rates for these tissues.

\section{Introduction}

Gastrointestinal tract (GIT) development is characterized by tremendous increases in mass, volume, and surface area [1]. In addition, tissue growth is accompanied by a differentiation which results in physical changes which include increased GIT, stomach (reticulo-rumen), and intestinal capacity (relative to body weight) and alterations in metabolic characteristics. Rumen development has a clear and major impact on the digestive capabilities and supply of substrates to the growing ruminant [2]. Thus, understanding the control of growth and differentiation in the various segments' capacity of GIT is essential to evaluate the growth of noncarcass components of growing lambs and the development of improved feeding regimes and high carcass yield [3-5].

In meat production systems, an increase in slaughter weight of lambs may result in higher productivity and give more flexibility to the production system [6]. Traditionally, lambs in Turkey as well as in most parts of the world are slaughtered between weaning at approximately 3 to 6 months of age with slaughter weights of 10 to $12 \mathrm{~kg}$ for suckling lambs, 20 to $22 \mathrm{~kg}$ for light lambs, 30 to $32 \mathrm{~kg}$ for early fattening lambs, and 40 to $42 \mathrm{~kg}$ for late fattening lambs [7, 8]. As reported by Carvalho et al. [9] and Galvani et al. [10], proportions of different noncarcass components such as GIT, stomach, and intestine expressed as percentage of the body weight at slaughter and also the proportion of gastrointestinal content are the main factors that affect carcass yield. A high feed efficiency cannot always represent a high efficiency of food production, because some organs can be proportionally greater at more advanced maturity, dropping the retention of tissues in the carcass [11]. In order to achieve higher weight and quality carcass, necessary nutritional interventions are required in lamb from birth till slaughter [12]. Therefore, knowledge about growth rate from distinct body components can help to determine an adequate slaughter weight in 
which carcass yield will be maximized [10], whereas the study of growth rate of some organs with high metabolic activity including gastrointestinal organs can contribute to improving the understanding on factors that affect nutritional requirements of the animals [13].

Although a number of studies have been conducted to elucidate the GIT development and growth $[7,10,14,15]$, little information is available on the GIT characteristics and the influence of different slaughter weights on the $\mathrm{pH}$ values in the various segments (rumen, jejunum, and caecum) of GIT of especially the Karayaka ram lambs, which is one of the indigenous breeds reared on the coastline of the Black Sea region of Turkey and well adapted to the wet climate of the region. Thus, the GIT characteristics such as weights of whole GIT, stomach, and intestine, and lengths of body, intestine, and caecum should be studied at different slaughter weights. The present study was conducted to evaluate the growth of these GIT components of growing lambs, to provide increase in GIT and some segments which are closely related with the body weight of the animal, to determine the relationship among slaughter body weight (SBW) and empty body weight (EBW), whole GIT, and some segments; it is aimed to examine the influence of different slaughter weights on the $\mathrm{pH}$ values of the various segments (rumen, jejunum, and caecum) of the lamb GIT.

\section{Material and Methods}

The study was carried out at the experimental farm of the Gaziosmanpaşa University, Faculty of Agriculture, Tokat, Turkey, situated at $40^{\circ} 31^{\prime} \mathrm{N}, 36^{\circ} 53^{\prime} \mathrm{E}$, and $650 \mathrm{~m}$ above sea level. Long term average annual temperature and relative humidity in this region vary from 8.1 to $14.2^{\circ} \mathrm{C}$ and between $56 \%$ and $73 \%$ [16]. The study was conducted complying with the EC 8 Directive 86/609/EEC and approved by Ethical Committee of Gaziosmanpaşa University for Experimental Animals (protocol number: 2011/046) and ascertained that the experiment is not an unnecessary repetition of previous experiments.

The winter born $(n=31)$ singleton indigenous Karayaka male lambs were used in this study. These animals were obtained from a study conducted to determine carcass and meat quality traits of Karayaka lambs at different slaughter weights in our institute [17]. Lambs were randomly assigned to one of five following slaughter weights: $30(n=7), 35$ $(n=6), 40(n=7), 45(n=6)$, and $50(n=5) \mathrm{kg}$ of body weight at fast. For this reason, lambs weaned at $42.3 \pm$ 2.20 days of age were treated for internal parasites, drenched with anthelmintic preparation (Triclabendazole $12 \mathrm{mg} / \mathrm{kg}$; Levamisole $7.5 \mathrm{mg} / \mathrm{kg}$ ), and housed together in $4 \times 6 \mathrm{~m}$ pens, equipped with feeders and a water source, and fed ad libitum under feedlot system in a naturally ventilated animal house.

Concentrate feed, mineral stone, and fresh water are given ad libitum in fattening period, whereas the forage lentil straw is given only $100 \mathrm{~g} / \mathrm{lamb} /$ day during in the experiment. Feed was intended to provide nutrient requirements for fattening [18]. The chemical composition of the feed supplements is presented in Table 1. Dry matter (method 930.15), crude protein (method 954.01), and fat by ether
TABLE 1: Composition of experimental concentrate feed and red lentil straw.

\begin{tabular}{lcc}
\hline Item & $\begin{array}{c}\text { Concentrate } \\
\text { feed }\end{array}$ & $\begin{array}{c}\text { Red lentil } \\
\text { straw }\end{array}$ \\
\hline Metabolizable energy (Mcal/kg) & 2.77 & 2.01 \\
Nutrients (\%) & 92.00 & 91.30 \\
$\quad$ Dry matter & 20.63 & 5.78 \\
Crude protein & 2.60 & 1.49 \\
Ether extract & 10.40 & 9.60 \\
Ash & 37.96 & 56.29 \\
Neutral detergent fibre & 26.39 & 55.59 \\
Acid detergent fibre &
\end{tabular}

extract were measured using the automated Tecator Soxtec System HT6 (Application note AN 301; FOSS North America, Eden Prairie, MN, USA), and crude ash (method 942.05) of dietary ingredients were determined according to AOAC [19]. The contents of neutral detergent fibre (NDF) and acid detergent fibre (ADF) were generated according to van Soest et al. [20] using the ANKOM A200/220 Fiber Analyzer filter bag technique (ANKOM Technology Corp., Fairport, NY, USA).

Before slaughter, the lambs were fasted for $16 \mathrm{~h}$ with free access to water. Also, body length (art. humeri-tuber ichii) was determined with measuring stick and measuring tape. When lambs reached $30,35,40,45$, and $50 \mathrm{~kg}$ of LW during fattening period, they were transported to a local licensed abattoir, and they were slaughtered following standard commercial slaughter procedures [21]. The digestive tract including the mouth, tongue, salivary glands, esophagus, four compartment stomach (rumen, reticulum, omasum, and abomasum), pancreas, gall bladder, small intestine (duodenum, jejunum, and ileum), and large intestine (caecum, colon, and rectum) was removed and weighed to get the weight of the full (GIT), and then emptied of its contents, washed, drained, and weighed to get the weight of the GIT content. GIT content was then subtracted from the SBW to determine empty body weight (EBW). Empty body weight (EBW) was calculated by the difference between SBW and the weight of the gastrointestinal contents [10]. Following exsanguinations, empty stomach (reticulo-rumen complex) and intestine weight were weighed and recorded [22]. As there is no distinct division between the rumen and the reticulum, they are often referred to together (reticulorumen). The rumen was opened, and the contents were removed before the organ was washed by hand and the external fat was then removed [23]. Length of the intestine was measured with measuring stick and measuring tape [24]. Empty GIT, stomach, and intestine weights were weighed (absolute weight) and expressed (relative weight, \% of SBW) per unit of body weight at slaughter. Hence, the relative weight contributions of these non-carcass components to SBW or their commercial yields were determined.

Before evisceration, the $\mathrm{pH}$ values of rumen, jejunum, and caecum digestas were immediately determined using a digital pH meter (Sartorious PP15, AG Weender Landstrasse 
TABLE 2: Slaughter body (SBW) and empty body (EBW) weights (kg), absolute weights (kg) and length (m), and relative weights (\% of SBW) of gastrointestinal tract segments of Karayaka ram lambs.

\begin{tabular}{|c|c|c|c|c|c|c|c|c|}
\hline \multirow{2}{*}{ Variable } & \multicolumn{5}{|c|}{ Slaughter weight categories (kg) } & \multirow{2}{*}{$\operatorname{SEM}^{(1)}$} & \multicolumn{2}{|c|}{$P$} \\
\hline & $30(n=7)$ & $35(n=6)$ & $40(n=7)$ & $45(n=6)$ & $50(n=5)$ & & $L^{(2)}$ & $Q^{(3)}$ \\
\hline \multicolumn{9}{|l|}{ Weight of } \\
\hline Slaughter body & 30.1 & 35.6 & 40.3 & 45.1 & 50.6 & 1.23 & & \\
\hline Empty body & 27.4 & 32.4 & 37.4 & 41.8 & 47.1 & 1.19 & $* * *$ & NS \\
\hline Gastrointestinal tract & 5.76 & 6.34 & 6.86 & 6.89 & 7.60 & 0.200 & * & NS \\
\hline Stomach & 0.82 & 0.86 & 0.91 & 0.95 & 1.06 & 0.019 & $* * *$ & NS \\
\hline Intestine & 1.12 & 1.04 & 1.04 & 1.03 & 1.06 & 0.022 & * & NS \\
\hline Gastrointestinal content & 2.70 & 3.18 & 2.90 & 3.28 & 3.52 & 0.145 & NS & * \\
\hline \multicolumn{9}{|l|}{ Length of } \\
\hline Body & 0.59 & 0.60 & 0.64 & 0.63 & 0.68 & 0.008 & $* * *$ & NS \\
\hline Intestine & 34.6 & 34.2 & 37.8 & 35.1 & 35.4 & 0.44 & NS & $*$ \\
\hline Caecum & 0.34 & 0.38 & 0.40 & 0.37 & 0.43 & 0.010 & $*$ & NS \\
\hline \multicolumn{9}{|l|}{ Relative weight of } \\
\hline Gastrointestinal tract & 19.1 & 17.8 & 17.0 & 15.3 & 15.0 & 0.48 & * & NS \\
\hline Stomach & 2.7 & 2.4 & 2.3 & 2.1 & 2.1 & 0.05 & $* * *$ & NS \\
\hline Intestine & 3.7 & 2.9 & 2.6 & 2.1 & 2.1 & 0.12 & $* * *$ & NS \\
\hline Gastrointestinal content & 8.9 & 8.9 & 7.2 & 7.3 & 7.0 & 0.39 & $*$ & NS \\
\hline
\end{tabular}

94-108, Goettingen, Germany). In the present study, the $\mathrm{pH}$ values were determined in five slaughter weights of rumen, jejunum, and caecum because rumen and intestine digesta $\mathrm{pH}$ values are dependent on sampling location within rumen and intestine. The $\mathrm{pH}$ probe was kept in the rumen, duodenum, and caecum until the $\mathrm{pH}$ reading was stabilized, and $\mathrm{pH}$ value was recorded [23].

Data were analyzed in a completely randomized design by regression. Thus, model included linear and quadratic effects as well as the lone main effect of slaughter weight, using the obtained values as independent variables. All analyses were performed using the SPSS statistical package [25]. Regression equations and bivariate correlations displaying the relationship among slaughter weight and weights of GIT, stomach, and intestine and lengths of body, intestine, and caecum were to be examined by means of regression procedure of SPSS. To verify if $b$ is significant, the $t$-test was used. Results are presented as means and a pooled SEM (unless otherwise stated).

\section{Results}

The SBW, EBW, the absolute weights and length, and the relative weights of whole GIT and their segments of Karayaka ram lambs are presented in Table 2. The effects of the SBW for the absolute weights of GIT $(P<0.05)$, stomach $(P<0.001)$, and intestine $(P<0.05)$, the lengths of body $(P<0.001)$ and caecum $(P<0.05)$, and the relative weights of GIT $(P<$ $0.05)$, stomach $(P<0.001)$, intestine $(P<0.001)$, and the gastrointestinal content $(P<0.05)$ were linear whereas those for the absolute weight of gastrointestinal content $(P<0.05)$ and the length of intestine were quadratic.
Estimated parameters for the regression equations of the empty body weight, whole GIT, and their segments and bivariate correlations displaying the relationship among these variables and slaughter weight are presented in Table 3 . The relationships between the SBW and EBW $\left(r^{2}=0.986, P<\right.$ $0.001)$ and the weights of GIT $\left(r^{2}=0.329, P<0.01\right)$ and stomach $\left(r^{2}=0.512, P<0.01\right)$ and the length of body $\left(r^{2}=0.376, P<0.01\right)$ and caecum $\left(r^{2}=0.145, P<0.05\right)$ were significant. The relationship between the EBW and SBW can be expressed by the following linear equation $\left(r^{2}=0.986\right.$; standard error of the estimate $=0.813, n=31)$ : EBW, $\mathrm{kg}=$ $-1.81( \pm 0.818)+[0.968( \pm 0.200) \times$ SBW, $\mathrm{kg}]$.

The intestine length to body length ratio, stomach weight to gastrointestinal weight ratio, intestine weight to gastrointestinal weight ratio, and intestine length to intestine weight ratio in Karayaka ram lambs slaughtered at different weights are presented in Table 4. The effects of the SBW were quadratic $(P<0.05)$ for the ratios of stomach weight to GIT weight and intestine length to intestine weight, while for theintestine weight to GIT weight ratio $(P<0.001)$, this effect was linear.

The $\mathrm{pH}$ of contents from various segments of the GIT is presented in Table 5. The effects of the SBW were linear $(P<0.05)$ for the rumen $\mathrm{pH}$ while for the caecum $\mathrm{pH}(P<$ 0.05), these effects were quadratic. A search of the literature indicated a lack of information on $\mathrm{pH}$ values of the various segments of the GIT in lambs slaughtered at different body weights.

\section{Discussion}

In general, a majority of the parameters measured exhibited linear relationships with SBW, with the exception of 
TABLE 3: Estimated parameters for the regression equations of the empty body weight (EBW), whole gastrointestinal tract (GIT), and some segments of GIT and bivariate correlations displaying the relationship among these variables and slaughter weight.

\begin{tabular}{|c|c|c|c|c|c|c|}
\hline Component & $a$ & $b$ & $\mathrm{SE}^{\dagger}$ & $t$ & $r^{2}$ & $\mathrm{SE}^{\S}$ \\
\hline EBW & -1.808 & 0.968 & 0.200 & $47.374^{* * *}$ & $0.986^{* * *}$ & 0.813 \\
\hline GIT weight & 2.934 & 0.093 & 0.024 & $3.888^{* * *}$ & $0.329^{* *}$ & 0.957 \\
\hline Stomach weight & 0.463 & 0.011 & 0.002 & $5.707^{* * *}$ & $0.512^{* *}$ & 0.079 \\
\hline Intestine weight & 1.215 & -0.004 & 0.003 & $-1.444^{\mathrm{NS}}$ & $0.063^{\mathrm{NS}}$ & 0.123 \\
\hline Body length & 47.103 & 0.390 & 0.090 & $13.033^{* * *}$ & $0.376^{* *}$ & 3.594 \\
\hline Intestine length & 32.561 & 0.072 & 0.060 & $1.195^{\mathrm{NS}}$ & $0.044^{\mathrm{NS}}$ & 2.407 \\
\hline Caecum length & 25.258 & 0.321 & 0.142 & $2.257^{*}$ & $0.145^{*}$ & 5.462 \\
\hline
\end{tabular}

$a$ : the intercept of the linear regression; $b$ : the relative growth or regression coefficient; $\mathrm{SE}^{\dagger}$ : standard error of the regression coefficient, $\mathrm{SE}^{\S}:$ standard error of the estimate, ${ }^{\mathrm{NS}} \mathrm{P}>0.05 ;{ }^{*} \mathrm{P}<0.05 ;{ }^{* *} P<0.01 ;{ }^{* * *} \mathrm{P}<0.001$.

TABLE 4: Ratios between the whole GIT and selected segments in the Karayaka ram lambs slaughtered at different weights.

\begin{tabular}{|c|c|c|c|c|c|c|c|c|}
\hline \multirow{2}{*}{ Variable } & \multicolumn{5}{|c|}{ Slaughter weight categories (kg) } & \multirow{2}{*}{$\operatorname{SEM}^{(1)}$} & \multicolumn{2}{|c|}{$P$} \\
\hline & $30(n=7)$ & $35(n=6)$ & $40(n=7)$ & $45(n=6)$ & $50(n=5)$ & & $L^{(2)}$ & $Q^{(3)}$ \\
\hline IL to $\mathrm{BL}$ & 58.7 & 57.6 & 58.7 & 55.9 & 52.3 & 0.97 & NS & NS \\
\hline SW to GITW & 14.5 & 13.6 & 13.6 & 14.0 & 14.2 & 0.36 & NS & * \\
\hline IW to GITW & 19.8 & 16.3 & 15.5 & 13.8 & 14.4 & 0.58 & $* *$ & NS \\
\hline IL to IW & 3.2 & 3.0 & 2.8 & 2.7 & 3.0 & 0.06 & NS & * \\
\hline
\end{tabular}

IL to BL: intestine length to body length ratio; SW to GITW: stomach weight to gastrointestinal weight ratio; IW to GITW: intestine weight to gastrointestinal weight ratio; IL to IW: intestine length to intestine weight ratio.

${ }^{(1)}$ Standard error of the mean; ${ }^{(2)}$ linear and ${ }^{(3)}$ quadratic effects of increasing slaughter weight; NS: nonsignificant $(P>0.05) ;{ }^{*} P<0.05 ;{ }^{* *} P<0.01$.

TABLE 5: Selected segment pH of gastrointestinal tract in Karayaka ram lambs slaughtered at different weights.

\begin{tabular}{lcccccccc}
\hline \multirow{2}{*}{ Variable } & \multicolumn{4}{c}{ Slaughter weight categories $(\mathrm{kg})$} & \multicolumn{2}{c}{ SEM $^{(1)}$} & $L^{(2)}$ & $Q^{(3)}$ \\
\hline Rumen pH & $30(n=7)$ & $35(n=6)$ & $40(n=7)$ & $45(n=6)$ & $50(n=5)$ & 7.08 & 0.419 & $*$ \\
Jejunum pH & 6.87 & 6.91 & 6.98 & 6.84 & 6.06 & 0.602 & NS \\
Caecum pH & 6.00 & 6.05 & 6.09 & 6.01 & NS \\
\hline${ }^{(1)}$ Standard & 6.59 & 6.77 & 6.64 & 6.47 & 0.036 & NS & $*$ \\
\hline
\end{tabular}

${ }^{(1)}$ Standard error of the mean; ${ }^{(2)}$ linear and ${ }^{(3)}$ quadratic effects of increasing slaughter weight; NS: nonsignificant $(P>0.05) ;{ }^{*} P<0.05$.

digesta and length and cecal $\mathrm{pH}$ which exhibited a quadratic relationship. These results confirm that the highest carcass yield obtained from lambs slaughtered immediately after weaning $[15,26]$ although changes in the carcass yield as the SBW increased were not presented in the current study. The absolute weights of whole GIT and stomach increased linearly whereas that of intestine decreased as the SBW increased. The functional maturity of the GIT is essential for the survival and growth of postnatal animals [1]. Therefore, the growth patterns of different body components such as whole GIT, stomach, and intestines in relation to SBW were decreased linearly as the SBW increased. The relative weights of noncarcass components were greater in lambs slaughtered at 30 and $35 \mathrm{~kg}$ of body weight than those in lambs slaughtered at 40,45 , and $50 \mathrm{~kg}$ of body weight. These results indicate that the changes in the relative weight contributions of noncarcass components to SBW affected the SBW or commercial carcass yields.

In the study reported by Abdullah and Qudsieh [7], slaughtering Awassi ram lambs at weights up to $30 \mathrm{~kg}$ resulted in higher dressing-out percentage and better carcass characteristics than ram lambs slaughtered at heavier weights. Lambs with heavier weights of stomach and intestine may have lower carcass yield because the gastrointestinal content influenced carcass yield [4]. Therefore, when taking account of the change in GIT weight with increasing SBW and the quadratic change in contents, the optimal body weight for slaughter may be recommended as $40-45 \mathrm{~kg}$ for Karayaka male lambs. Indeed the gastrointestinal content as a proportion of SBW, which indicates the ratio of EBW to SBW, decreased from $8.9 \%$ in lambs slaughtered at body weight of $30 \mathrm{~kg}$ to $7.0 \%$ in animals slaughtered at more elevated body weights. This may be explained by the fact that the proportion of gastrointestinal content is directly related to the ruminal development [10], which is stimulated by the dry matter intake, mainly from fibrous foods [2]. Accordingly, for Karayaka lambs raised in confinement after weaning at 42 days and feeding until 150 days of age, slaughter weight targets should probably be increased to $40-45 \mathrm{~kg}$ without detrimental effects on carcass yield [17], confirming the suggestions of Santos-Silva and Portugal [27] for Merino Branco lambs. The results on the absolute weights and length and the relative weights of whole GIT and their segments are similar to those reported by Galvani et al. [10] in Texel crossbred lambs slaughtered at 25,30, or $35 \mathrm{~kg}$ of body weight. Indeed, Galvani et al. [10] reported that an effect of the SBW 
on the absolute weights and relative weights of GIT, stomach, and intestine was observed while there is no effect on weight of stomach contents. Also, Balci and Karakas [14] found that effect of the SBW on the absolute weight of GIT in Karayaka ram lambs slaughtered at 25,30 , or $35 \mathrm{~kg}$ of body weight was significant.

The development of stomach is directly related to feed intake [2]. Priolo et al. [28] reported that the increase in weight of the rumen and small intestine is an indication that they have an important role in ensuring the efficiency of feed utilization in animals. However, it was not clear whether lambs slaughtered at a high body weight were more efficient in terms of feed intake and feed efficiency due to the difference in relative GIT weights since there were no data on the amount of feed consumed by lambs in the current study. In the study, there is the linear decrease in the absolute and relative weights of intestine while there is a quadratic change in the length of intestine (Table 3 ). Therefore, the proportion of intestine was affected by the slaughter weight, as reported by Galvani et al. [10].

Correlation coefficients found in the present study are lower than those observed by Galvani et al. [10] for the small and large intestines; our results may be analyzed by using the regression equations of each of the GIT segments, as a function of SBW, with the exception of intestine weight and length. In the present study, the EBW, the weights of GIT and their segments such as stomach and intestine caecum increased at a steady rate between all slaughter weights, as reported by Balci and Karakas [14], Abdullah and Qudsieh [7], and Galvani et al. [10].

The results with respect to the ratios between the whole GIT traits and their segments indicate that the ratios of stomach weight to GIT weight and intestine length to intestine weight and the intestine weight to GIT weight are likely to affect the fattening performance of lambs, as it was observed in our previous study [29]. Also, these results may suggest that different parts of the GIT had a constant length relative to the intestine weight. The quadratic effect of the SBW for the ratios of intestine length to intestine weight may be explained by the fact that stimulating the functional role of the GIT at an early age seems to increase its length [5].

The $\mathrm{pH}$ values observed in the present study were within ranges (6.00 to 7.08) which most rumen microbes can typically thrive [29-31]. The GIT development may be stimulated by $\mathrm{pH}$ values of rumen and caecum because volatile fatty acids may result in significant changes in intestinal growth characteristics of developing ruminants [1]. Ruminal $\mathrm{pH}$ drops below physiological levels when ruminants consume excessive amounts of rapidly fermentable (nonfibre) carbohydrates [32,33]. Krause and Oetzel [33] noted that, to maintain ruminal $\mathrm{pH}$ within a physiological range of about 5.5 to 7.0, ruminants possess highly developed systems such as carefully regulating their feed intake and the ability of the rumen to rapidly absorb organic acids. Therefore, the differences in influence of SBW on the GIT pH may be explained by differences in the nature of regulation of ruminal $\mathrm{pH}$ described above.

\section{Conclusions}

The results indicated that, for all parameters studied, except gastrointestinal content, intestine length and caecum $\mathrm{pH}$ increased at a steady rate between all slaughter weights and also that different body components present distinct growth patterns; GIT, stomach, and intestine are, proportionally, greater in the younger Karayaka sheep. Also, growth and development of whole GIT and specific segments increased with SBW, and it is evident that they was not reached a plateau for except intestine length. The changes in the relative weights of the whole GIT and their segments as well as the relative weight of the gastrointestinal content as the SBW increased suggested that 40 and $45 \mathrm{~kg}$ of slaughter weight for Karayaka male lambs are recommended. However, because the response in terms of carcass yield and quality parameters can vary depending on the degree of maturity of the animals at slaughter, the age or body weight of the lamb at slaughter should be determined. However, because the response in terms of carcass yield and quality parameters can vary depending on the degree of maturity of the animals at slaughter, the age or body weight of the lamb at slaughter should be determined taking into account demands and prices for these carcass components in different markets. These data may be used in selection of optimal slaughter weight decisions on farm regarding Karayaka ram lambs.

\section{Conflict of Interests}

The authors declare that there is no conflict of interests regarding the publication of this paper.

\section{Acknowledgments}

The study was supported by The Scientific and Technological Research Council, TUBITAK (TOVAG-111O848). The authors are grateful for the support of the staff and facilities of Animal Science Department, Agriculture Faculty, Gaziosmanpaşa University. The authors thank Associate Professor Dr. H. Önder for his assistance with the statistical analysis.

\section{References}

[1] R. L. Baldwin, "Sheep gastrointestinal development in response to different dietary treatments," Small Ruminant Research, vol. 35, no. 1, pp. 39-47, 1999.

[2] R. L. Baldwin, K. R. McLeod, J. L. Klotz, and R. N. Heitmann, "Rumen development, intestinal growth and hepatic metabolism in the pre- and postweaning ruminant," Journal of Dairy Science, vol. 87, no. 1, pp. E55-E65, 2004.

[3] F. Gao, X. Z. Hou, and Y. C. Liu, "Effect of intrauterine growth restriction on weight and cellularity of gastrointestinal tract in postnatal lambs," Canadian Journal of Animal Science, vol. 88, no. 1, pp. 107-112, 2008.

[4] F. G. Ríos, A. Gómez-Vázquez, J. M. Pinos-Rodríguez et al., "Effect of breed on performance and carcass characteristics of Mexican hair sheep," South African Journal of Animal Science, vol. 41, no. 3, pp. 275-279, 2011. 
[5] G. A. A. Ward, "Effect of pre-weaning diet on lamb's rumen development," American-Eurasian Journal of Agricultural \& Environmental Sciences, vol. 3, no. 4, pp. 561-567, 2008.

[6] J. Santos-Silva, I. A. Mendes, and R. J. B. Bessa, "The effect of genotype, feeding system and slaughter weight on the quality of light lambs 1. growth, carcass composition and meat quality," Livestock Production Science, vol. 76, no. 1-2, pp. 17-25, 2002.

[7] Y. A. Abdullah and R. I. Qudsieh, "Carcass characteristics of Awassi ram lambs slaughtered at different weights," Livestock Science, vol. 117, no. 2-3, pp. 165-175, 2008.

[8] Z. Ulutaş, M. Kuran, A. Önenç et al., "Yerli ırklarımızdan İvesi, Kivırcık, Akkaraman, Morkaraman, Karayaka, Anadolu Merinosu koyunlarında et kalitelerinin belirlenmesi," in 8 . Ulusal Zootekni Bilim Kongresi, p. 396, Çanakkale, Turkey, 2013.

[9] S. Carvalho, M. A. Brochier, J. Pivato, A. Vergueiro, R. C. Teixeira, and R. Kieling, "Desempenho e avaliação econômica da alimentação de cordeiros confinados com dietas contendo diferentes relações volumoso: concentrado," Ciência Rural, vol. 37, no. 5, pp. 1411-1417, 2007.

[10] D. B. Galvani, C. C. Pires, T. P. Wommer, F. de Oliveira, G. P. T. Kodayssi, and L. Griebler, "Postweaning growth of the noncarcass components of Texel crossbred lambs," Revista Brasileira de Zootecnia, vol. 39, no. 7, pp. 1558-1564, 2010.

[11] C. C. Pires, L. F. Silva, L. H. E. Farinatti, L. A. O. Peixoto, M. E. Fülber, and M. A. Cunha, "Crescimento de cordeiros abatidos com diferentes pesos. 2. Constituintes corporais," Ciência Rural, vol. 30, no. 5, pp. 869-873, 2000.

[12] R. S. Bhatt, M. K. Tripathi, D. L. Verma, and S. A. Karim, "Effect of different feeding regimes on pre-weaning growth rumen fermentation and its influence on post-weaning performance of lambs," Journal of Animal Physiology and Animal Nutrition, vol. 93, no. 5, pp. 568-576, 2009.

[13] C. L. Ferrel, "Contribution of visceral organs to animal energy expenditures," Journal of Animal Science, vol. 66, no. 3, pp. 2334, 1988.

[14] F. Balci and E. Karakas, "The effect of different slaughter weights on the fattening performance, slaughter and carcass characteristics of male Karayaka lambs," Turkish Journal of Veterinary and Animal Sciences, vol. 31, no. 1, pp. 25-31, 2007.

[15] P. Pérez, M. Maino, M. S. Morales, C. Köbrich, C. Bardon, and J. Pokniak, "Gender and slaughter weight effects on carcass quality traits of suckling lambs from four different genotypes," Small Ruminant Research, vol. 70, no. 2-3, pp. 124-130, 2007.

[16] MARA, The Master Plan of Tokat Province, Tokat, Statistical Data of Tokat Province, MARA, Tokat, Turkey, 2009.

[17] Y. Aksoy, Determination of carcass and meat quality traits of Karayaka lambs at different slaughter weight [Ph.D. thesis], Gaziosmanpasa University, Graduate School of Natural and Applied Sciences, Department of Animal Science, Tokat, Turkey, 2013.

[18] NRC, Nutrient Requirements of Small Ruminants: Sheep, Goats, Cervids, and New World Camelids, National Academy Press, Washington, DC, USA, 6th edition, 2007.

[19] AOAC, Official Methods of Analysis, Association of Official Analytical Chemists, Washington, DC, USA, 17th edition, 2000.

[20] P. J. van Soest, J. B. Robertson, and B. A. Lewis, "Methods for dietary fiber, neutral detergent fiber, and nonstarch polysaccharides in relation to animal nutrition.", Journal of dairy science, vol. 74, no. 10, pp. 3583-3597, 1991.

[21] Turkish Standards Institute, TS 52737 Butchery Animals-Rules for Slaughtering and Carcass Preparation, Ankara, Turkey, 1987.
[22] F. Balci and A. Orman, "The effects of short-term recombinant bovine somatotropin treatment on fattening performance, carcass composition and visceral organ weights in karayaka lambs in Turkey," Tropical Animal Health and Production, vol. 40, no. 4, pp. 255-260, 2008.

[23] A. Yıldırım, Z. Ulutaş, N. Ocak, E. Şirin, and Y. Aksoy, "A study on gastrointestinal tract characteristics of ram lambs with same weights from six common Turkish sheep breeds," South African Journal of Animal Science, vol. 44, no. 1, pp. 90-96, 2014.

[24] G. Stenheim, L. A. Nordheim, R. B. Weladji, Ø. Holand, and T. Ådnøy, "Digestive tract anatomy of Norwegian sheep: difference between breeds," Acta Agriculturae Scandinavica A: Animal Science, vol. 53, no. 3, pp. 155-158, 2003.

[25] SPSS, Statistics Base 17.0 for Windows User's Guide, SPSS, Chicago, Ill, USA, 2008.

[26] V. A. C. Santos, S. R. Silva, E. G. Mena, and J. M. T. Azevedo, "Live weight and sex effects on carcass and meat quality of "Borrego terrincho-PDO" suckling lambs," Meat Science, vol. 77, no. 4, pp. 654-661, 2007.

[27] J. Santos-Silva and A. V. Portugal, "The effect of weight on carcass and meat quality of Serra da Estrela and Merino Branco lambs fattened with dehydrated lucerne," Animal Research, vol. 50, no. 4, pp. 289-298, 2001.

[28] A. Priolo, D. Micol, J. Agabriel, S. Prache, and E. Dransfield, "Effect of grass or concentrate feeding systems on lamb carcass and meat quality," Meat Science, vol. 62, no. 2, pp. 179-185, 2002.

[29] A. Yıldırım, Z. Ulutaş, N. Ocak, and M. Kaptan, "Effects of birth weight and feeding system on fattening performance and feeding behavior of Karayaka male lambs," Italian Journal of Animal Science, vol. 12, no. 4, pp. 546-550, 2013.

[30] R. Franzolin and B. A. Dehority, "The role of $\mathrm{pH}$ on the survival of rumen protozoa in steers," Revista Brasileira de Zootecnia, vol. 39, no. 10, pp. 2262-2267, 2010.

[31] R. Franzolin, F. P. Rosales, and W. V. B. Soares, "Effects of dietary energy and nitrogen supplements on rumen fermentation and protozoa population in buffalo and zebu cattle," Revista Brasileira de Zootecnia, vol. 39, no. 3, pp. 549-555, 2010.

[32] J. R. Russell, A. W. Young, and N. A. Jorgensen, "Effect dietary corn starch intake on pancreatic amylase and intestinal maltase and pH in cattle," Journal of Animal Science, vol. 52, no. 5, pp. $1177-1182,1981$.

[33] K. M. Krause and G. R. Oetzel, "Understanding and preventing subacute ruminal acidosis in dairy herds: A review," Animal Feed Science and Technology, vol. 126, no. 3-4, pp. 215-236, 2006. 

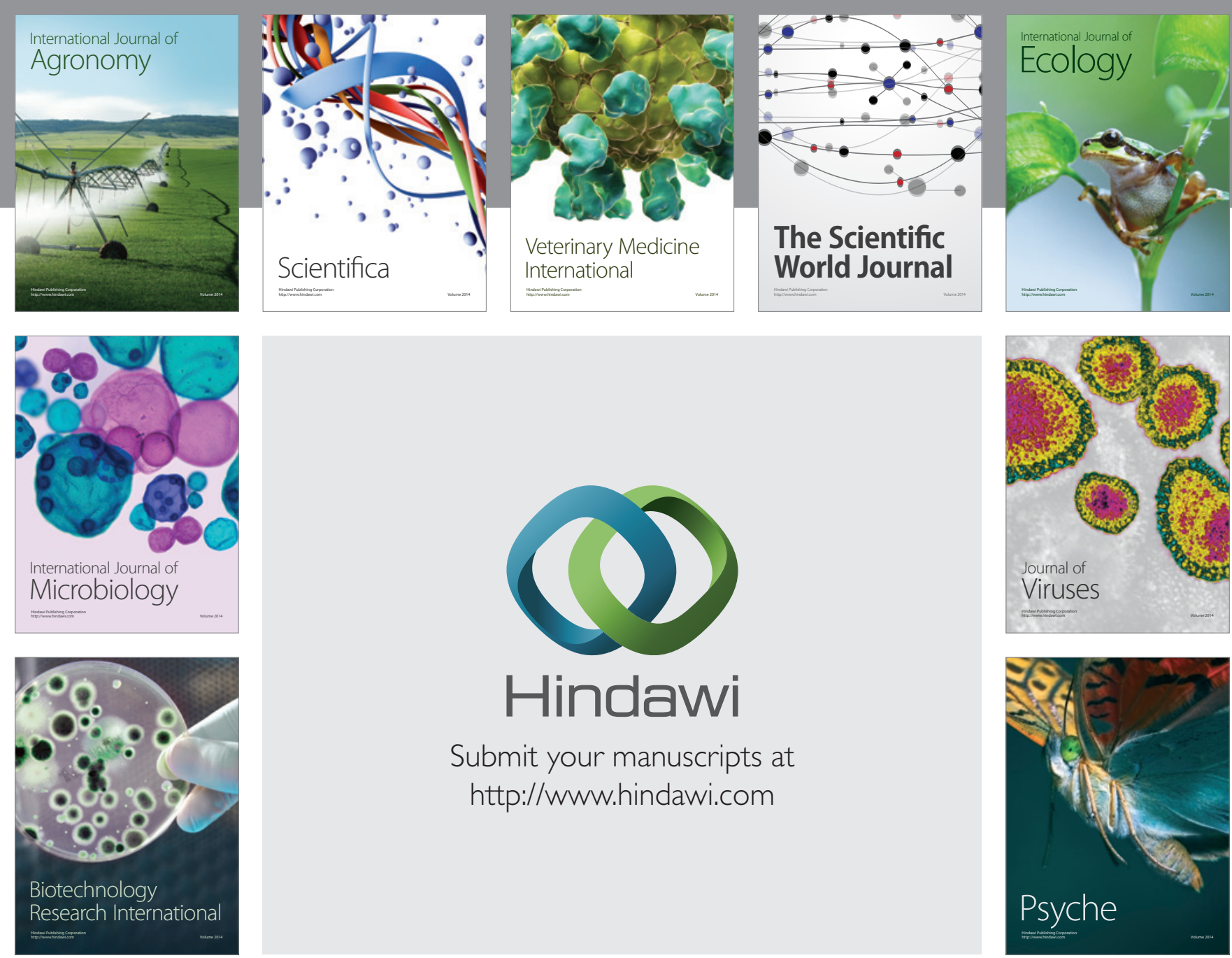

Submit your manuscripts at http://www.hindawi.com
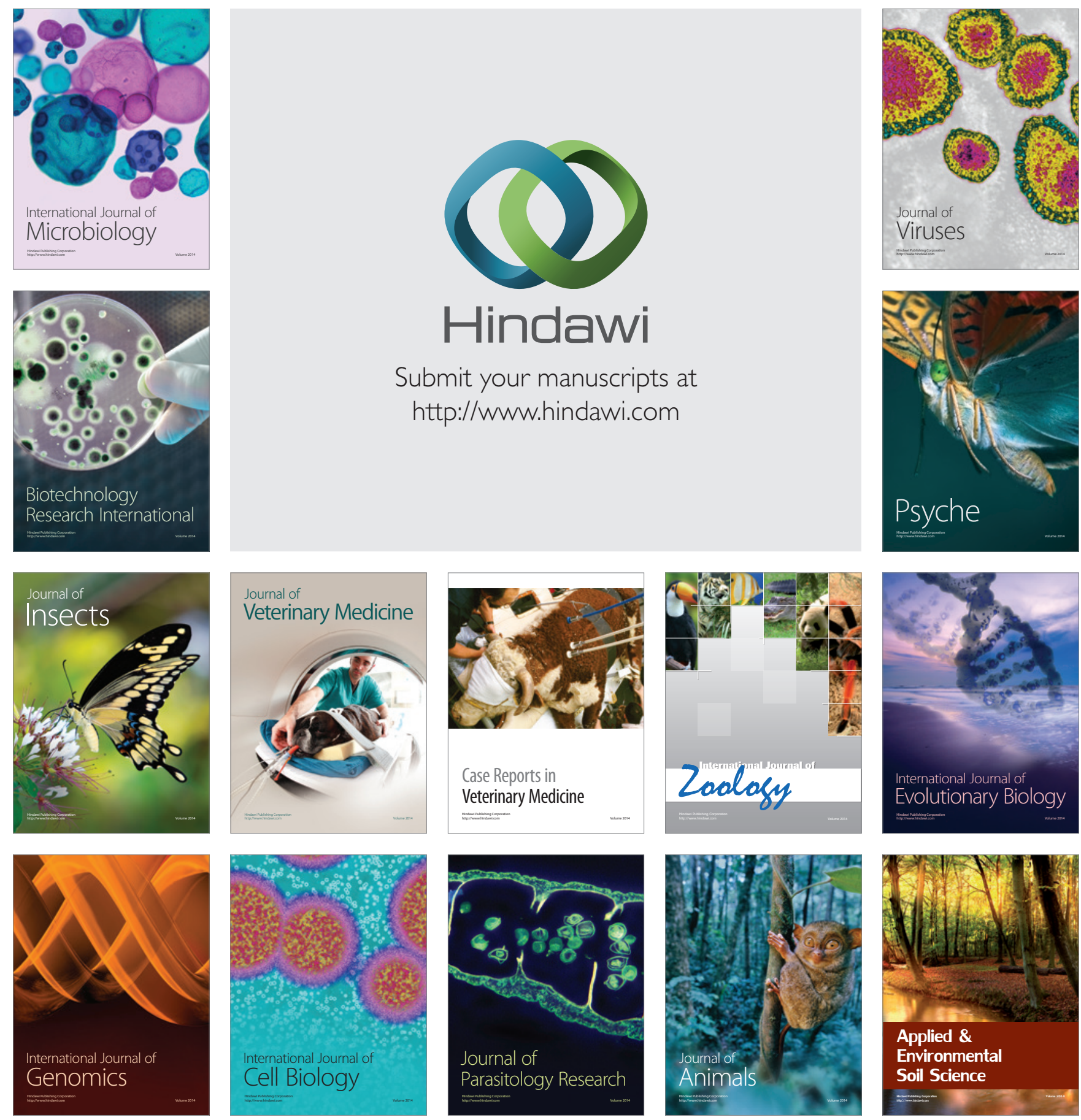